\title{
Eğik Çekme Yükü Etkisindeki Tekil Kazığın Üç Boyutlu Sayısal Analizi
}

\author{
Buse EMİRLER ${ }^{* 1}$, Mustafa TOLUN², Abdulazim YILDIZ ${ }^{3}$ \\ ${ }^{1}$ Çukurova Üniversitesi, Ceyhan Mühendislik Fakültesi, Inşaat Mühendisliği Bölümü, Adana \\ ${ }^{2}$ Adana Alparslan Türkeş Bilim ve Teknoloji Üniversitesi, Mühendislik Fakültesi, İnşaat \\ Mühendisliği Bölümü, Adana \\ ${ }^{3}$ Çukurova Üniversitesi, Mühendislik Fakültesi, İnşaat Mühendisliği Bölümü, Adana
}

Geliş tarihi: 11.01.2019

Kabul tarihi: 28.06 .2019

\section{Özet}

Bu çalışmada, eğik çekme yükü etkisindeki tekil kazık davranışı sayısal olarak analiz edilmiştir. Kum zemine gömülü, $\mathrm{L} / \mathrm{D}=8$ gömülme oranındaki tekil bir kazık farklı yük açılarında $\left(\alpha=0^{\circ}, 15^{\circ}, 30^{\circ}, 45^{\circ}, 60^{\circ}\right.$ ve $90^{\circ}$ ) çekmeye maruz bırakılmıştır. Sayısal analizler, sonlu eleman yöntemine dayalı Plaxis 3D bilgisayar programı kullanılarak yapılmıştır. Analizlerde; öncelikle, sonlu eleman sıkılığının etkisi araştırılmıştır. Programın sunduğu beş farklı ağ sıkılığında analizler gerçekleştirilmiş ve sıkılığın kazık kapasitesi üzerinde etkisinin kalmadığ 1 ince (fine) a ğ sıkılığında analizlerin yapılmasına karar verilmiştir. $90^{\circ}$ çekme açısına sahip kazıkta yapılan sayısal analizden elde edilen sonuç, literatürde yer alan teorik bir yöntemle karşılaştırılmış ve sayısal analizin kazık kapasitesini tahminindeki başarısı araştırılmıştır. Sayısal analiz ve teorik yöntemle elde edilen sonuçların oldukça uyumlu olduğu görülmüş ve sonrasında yapılan parametrik çalışmada, yükün düşey eksenle yaptığı açının artmasıyla kazık kapasitesinin azaldığı belirlenmiştir.

Anahtar Kelimeler: Eğik yük, Düşey kazık, Kum zemin, Sayısal analiz, Plaxis 3D

\section{Three Dimensional Numerical Analysis of Single Pile under Inclined Uplift Load}

\begin{abstract}
In this study, a single pile behaviour under inclined uplift load has been investigated, numerically. The single pile embedded in sand soil having the embedment ratio of 8 (L/D) has been exposed to the inclined load for different load angles $\left(\alpha=0^{\circ}, 15^{\circ}, 30^{\circ}, 60^{\circ}\right.$, and $\left.90^{\circ}\right)$. Numerical analyses have been performed by using Plaxis 3D computer program based on finite element method. Firstly, the effect of mesh density of finite element has been studied in the analyses. Five different mesh densities are available in Plaxis 3D ranging from very coarse to very fine. In this study, the meshes of finite element have been chosen as fine where the effect of mesh density is ended on the uplift capacity of single pile. The result obtained from the
\end{abstract}

*Sorumlu yazar (Corresponding author): Buse EMIRLER, bemirler@cu.edu.tr 
numerical analysis related to the single pile having the load angle of $90^{\circ}$ has been compared with a theoretical method in the literature and thanks to this, the success of the numerical analysis in the prediction of the uplift capacity of single pile has been studied. It has been understood that the results obtained from numerical analysis and theoretical method are in a very good agreement and in the parametric study afterwords, it has been observed that the uplift capaicty of single pile decreases with the increase of the load angle.

Keywords: Inclined load, Vertical pile, Sand soil, Numerical analysis, Plaxis 3D

\section{GíRiș}

Kazıklar, yapı yüklerini zeminin altındaki derin tabakalara taşıtmak amacıyla kullanılan yapı elemanlarıdır. Bu sebeple taşıyıcı sistemi oluşturan elemanların her birinde, yapı yüklerinin kazıklar aracılığıyla temel zeminine güvenli bir şekilde aktarmasını sağlayacak rijitlik, kararlılık, dayanım ve süneklik bulunmalıdır. Kazığa etkiyen yükler düşey ve yatay olmak üzere iki sınıfa ayrılır. Düşey yükler kazık eksenine paralel olarak etkirken, yatay yükler kazık eksenine dik olarak etkir. Üst yapıdan gelen yüklerin küçük olduğu durumlarda, yükler düşey kazıklarla güvenle taşınabilmektedir. Ancak, rıhtım ve dalgakıranların azıkları, köprü ayakları, petrol arama kuleleri, yüksek bacalar ve dayanma yapıları gibi yapıların temelleri oldukça yüksek mertebelerdeki yatay yük bileşenleri etkisinde kalabilmektedir. Bu yükler göz önüne alınmaksızın tasarlanıp inşa edilen düşey kazıkların, üst yapı yüklerini güvenli şekilde taşımaları olanaksızdır. $\mathrm{Bu}$ durumda yatay yükler göz önüne alınarak tasarlanan düşey kazıklarla veya bu kazıkların taşıma gücü açısından yetersiz kaldığı durumlarda ise eğik kazıklarla yüksek yatay taşıma gücü sağlanabilmektedir [1].

Kazıklar pratikte değişik problemlerde başarıyla kullanılabilmektedir. Çekme kazıkları, uzun yapılarda doğabilecek momentlere karş1 kullanılabilir. Su altında yapılan tesisler veya gömülü tanklar bu tip kazıkların kullanıldığı yerlere örnek olarak verilebilir. Yatay yüklü kazıklar, kazık eksenine dik uygulanan kuvvetlerin dengelenmesinde kullanılır. Kazık zemine eğik olarak yerleştirilmişse bu tip kazıklara eğik kazık denilir ve bu tip kazıklar aynı anda hem yatay hem de düşey yükleri taşıyabilirler (Şekil 1) [1].

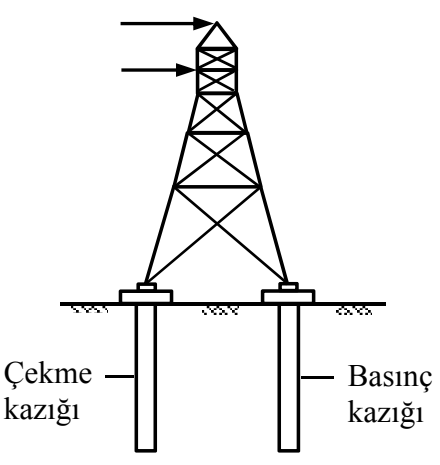

(a) yüksek gerilim hattı

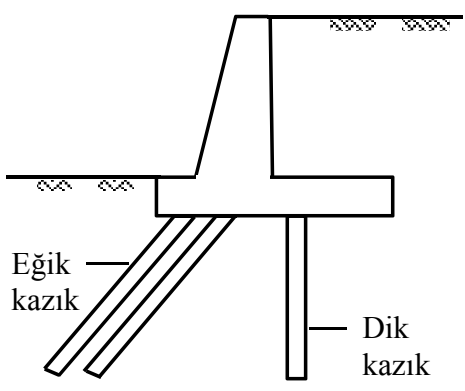

(b) istinat duvarı

Şekil 1. Farklı yüklere maruz kazıklı yapılar

Eğik çekme yüküne maruz kazıkların davranışını araştırmak için deneysel ve sayısal çalışmalar yapılmıştır. Chattopadhyay ve Pise [2], kum zemine gömülü düşey kazıkların çekme kapasitesini analitik bir yöntem kullanarak araştırmışlardır. Kazık boy-çap oranı, kazık sürtünme açısı ve içsel sürtünme açısı parametrelerinin çekme kapasitesinde önemli bir etkiye sahip olduğunu belirlemişlerdir. Ismael [3], kum zemine gömülü kazıkların eğik çekme davranışını arazi deneyleri ile araştırmıştır. $0^{\circ}, 30^{\circ}$ ve $60^{\circ}$ açıya sahip yükleme deneylerinde, $1,5 \mathrm{~m}$ uzuluğunda ve $101 \mathrm{~mm}$ çapında 
kazıklar kullanmıştır. Eğik yükleme deneyleri sonucunda hem düşey hem de yatay yönde göçme mekanizması oluşacağından, kazık kapasitesinin hesabında her iki doğrultudaki kapasitenin dikkate alınması gerektiğini vurgulamıştır. Yük açısının artmasıyla yatay kapasitenin arttığı, düşey kapasitenin ise azaldığı sonucuna ulaşmış ve elde ettiği sonuçları literatürdeki teorik bir yöntemle desteklemiştir. Veeresh ve Narasimha Rao [4], kil zemine gömülü eğik kazıkların çekme davranışını deneysel olarak incelemişlerdir. Kazık açısının artmasıyla çekme kapasitesinin azaldığını görmüşler ve bu azalmayı yüzey sürtünmesinde meydana gelen azalmayla ilişkilendirmişlerdir. AlShakarchi ve arkadaşları [5], kum zemine gömülü tekil eğik kazığın çekme yükü etkisindeki davranışını laboratuvar deneyleri yaparak araştırmışlardır. Eğik yükleme altında düşey ve eğik kazıkların çekme kapasitesi, çekme açısının artmasıyla artmış ve çekmenin yatay olduğu durumda kapasite maksimuma ulaşmıştır. Ayrıca negatif yönlü eğik kazıkların çekme yükünün pozitif yönlü eğik kazıklardan daha fazla olduğunu görmüşlerdir. Mroueh ve Shahrour [6], eğik çekme yüküne maruz düşey kazıkların davranışında zemin-kazık ara yüzeyinin etkisini incelemişlerdir. $\mathrm{Bu}$ amaçla üç boyutlu sonlu elemanlar programı ile analizler yapmışlardır. Analiz sonuçlarına göre, yük açısı ve zemin-kazık ara yüzeyinin kazığın eksenel davranışını büyük oranda etkilediğini, kazığın yatay davranışının ise bu faktörlerden bağımsız olduğunu belirlemişlerdir. Mroueh ve Shahrour [7], eğik çekme yüküne maruz eğik kazıkların davranışını üç boyutlu sonlu elemanlar analizi ile incelemişlerdir. Analiz sonuçları, yük açısının kazığın yatay ve eksenel davranışını etkilediğini göstermiş ve çekme kapasitesinin hem kazığın düşey eksenle yaptığı açıdan hem de uygulanan yükün kazık ekseniyle yaptığı açıdan etkilendiğini ortaya koymuştur. Korkmaz [8], düşey ve eğik kazıklı iskele yapılarında zemin-yapı etkileşimini sayısal olarak analiz etmiştir. DLH 2008 esaslarına göre doğrusal olmayan statik analizler yapmış ve farklı zemin koşulları için yatay yük taşıma kapasiteleri ile maksimum yer değiştirmeleri incelemiştir. Sağlam zemine oturan düşey kazıklı iskelelerde yatay yer değiştirmelerin yüksek mertebelerde olduğunu ancak kazık kesitlerinin daha çok zorlandığını, eğik kazıklı iskelelerde ise yatay yer değiştirmelerin düşük mertebelerde olsa bile gerilmeler açısından kazık kesitlerini aşırı zorladığını görmüştür. Nazir ve Nasr [9], kum zemine gömülü eğik kazıkların çekme dayanımını etkileyen parametreleri araştırmışlardır. Kum sıkılığı, kazı̆̆ın gömülme derinliği oranı ve açının etkisini laboratuvarda model deney yaparak belirlemişlerdir. S1k1 ve orta sıkılıktaki kum zeminde eğik kazıkların çekme kapasitesinin açının artmasıyla arttığını, ancak maksimum değere ulaştıktan sonra kapasitenin azaldığını görmüşlerdir. Çekme kapasitesinin maksimum değerinin $20^{\circ}$ 'de elde edildiğini ve bu değerde çekme kapasitesinin düşey kazık kapasitesinden yaklaşı \%21-31 daha fazla olduğunu tespit etmişlerdir. Gevşek zeminde ise kazık açısının artmasıyla çekme kapasitesinde azalma olduğu sonucuna ulaşmışlardır. Li ve arkadaşları [10], kum zemine gömülü tekil kazığın göçme zarfını sayısal olarak araştırmışlardır. Üç boyutlu çalışma ortamında yapılan analiz sonuçlarına göre düşey yükün artmasıyla kazığın yatay taşıma kapasitesi azalmıştır. Ayrıca, kazık başında eğilme momentinin varlığı yatay taşıma kapasitesini önemli oranda etkilemiş ve belirli bir düzlemdeki kapasite diyagramı eğik eliptik şekil oluşturmuştur. Reddy and Ayothiraman [11], hem çekme hem de yatay yüke maruz tekil kazığın davranışını deneysel olarak araştırmışlardır. Rijit ve flexible kazıkların davranışını üç farklı boy-çap oranı için incelemişlerdir. Bağımsız yüklemeye maruz kazıkların davranışının kombine yüklemeye maruz kazıkların davranışından önemli ölçüde farklı olduğunu görmüşlerdir. Kombine yüklemedeki yatay/çekme yük kapasitesinin önemli oranda arttığını, ancak bununla birlikte kazık başı dönmesi/deplasman değerinin de arttığını belirlemişlerdir. Jiang ve Li [12], yüzer tünellerde kullanılan eğik yüklemeye maruz düşey kazıkların davranışını sayısal analiz yaparak incelemişlerdir. Analizlerde, sonlu farklar yöntemine dayalı FLAC3D bilgisayar programını kullanmışlardır. Tekil kazı̆̆ $1 ; 0^{\circ}, 30^{\circ}, 45^{\circ}, 60^{\circ}$ ve $90^{\circ}$ açıya sahip çekme yüklemesine maruz bırakmışlardır. Yükleme açısının $30^{\circ}$ olduğu durumda maksimum kazık 
kapasitesine ulaşmışlar ve uygulamada kullanılmak üzere öneride bulunmuşlardır.

Bu çalışmada, kum zemine gömülü eğik çekme yüküne maruz tekil bir kazığın davranışı sayısal olarak incelenmiştir. Analizler, sonlu eleman yöntemine dayalı Plaxis 3D bilgisayar programı ile yapılmıştır. Yükün düşey eksenle yaptığı açının $(\alpha)$ kazık kapasitesine etkisi araştırılmıştır.

\section{MATERYAL VE METOT}

\subsection{Sayısal Analiz}

Sonlu eleman yöntemi; diş etkilere maruz fiziksel bir sistemin davranışını idare eden diferansiyel denklemlerin yaklaşık sayısal çözümlerini elde etmek için kullanılan bilgisayar destekli bir hesaplama tekniğidir. Sonlu eleman yönteminin en önemli özelliği herhangi bir standart formülasyona uymayan problemleri oldukça başarılı bir şekilde çözümleyebilmesidir. Yöntemin ana fikri; Şekil 2'de görüldüğü gibi analiz edilecek problem geometrisini basit geometrik şekle sahip çok sayıdaki küçük elemanlara ayırmaktır. Sonlu eleman adı verilen bu küçük bölgelerin birleşimi sonlu eleman ağı (mesh) olarak adlandırılır. Sonlu eleman ağını oluşturan elemanlar birbirlerine elemanların kenarlarında yer alan düğüm noktaları (node) aracılığı ile bağlıdır. Analiz edilecek sürekli ortamın sonlu elemana ayrılması ile sonsuz sayıda serbestlik derecesine sahip sürekli fiziksel model ortamı sonlu sayıda serbestlik derecesine sahip ayrıklaştırılmış model ile temsil edilmektedir.

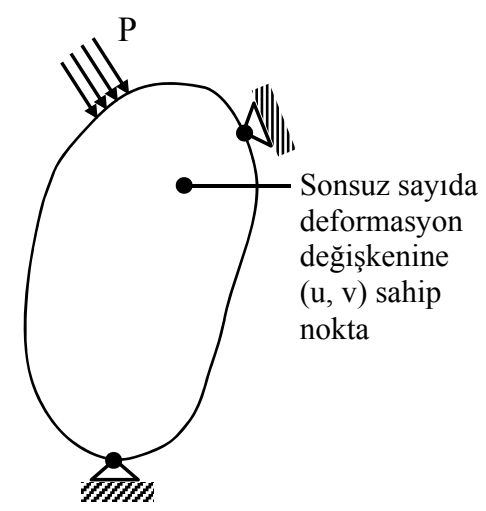

(a) Gerçek model (sürekli ortam)

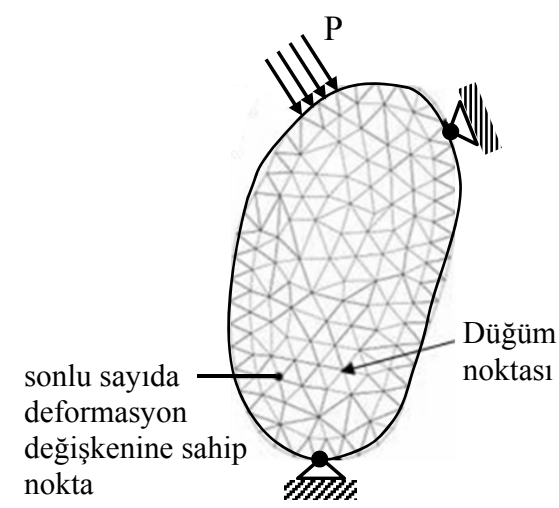

(b) Analiz edilen model (sonlu elemana ayrılmış ortam)

Şekil 2. Sonlu eleman yöntemi

Bir problemin sonlu eleman yöntemi ile analizi; deplasman yöntemi, kuvvet yöntemi ya da karma yöntemlerden birisi kullanılarak gerçekleştirilir. Geoteknik mühendisliğindeki problemlerin çoğunluğu deplasman yöntemi kullanılarak çözümlenmektedir. Deplasman yönteminde; bilinmeyen deplasman olup gerilme ve birim şekil değiştirmeler ikincil büyüklükler olarak deplasmanların tanımlanmasına bağlı olarak elde edilirler. Bilinmeyen büyüklük olan deplasmanların bir sonlu elemandaki değişimi interpolasyon fonksiyonları kullanılarak tanımlanmaktadır. İnterpolasyon fonksiyonları olarak genellikle polinomlar seçilmektedir. Bir sonlu eleman ve bu sonlu elemanı çevreleyen düğüm noktaları arasındaki ilişki Eşitlik 1 kullanılarak tanımlanmaktadır.

$[\mathrm{k}]_{\mathrm{e}}\{\mathrm{u}\}_{\mathrm{e}}=\{\mathrm{f}\}_{\mathrm{e}}$

Eşitlik 1'deki eleman deplasman vektörü $\{\mathrm{u}\}_{\mathrm{e}}$ bilinmeyen olup, uygulanan kuvvetler etkisinde düğüm noktalarının nasıl hareket edeceğini tanımlamaktadır. Eleman rijitlik matrisi $[\mathrm{k}]_{\mathrm{e}}$; eleman özellikleri, malzeme özellikleri ve eleman geometrisi kullanılarak elde edilir. Eleman yük vektörü $\{f\}_{\mathrm{e}}$ ise eleman üzerinde etkili olan yükleri tanımlamaktadır. Her bir elemana ait rijitlik matrislerinin ve eleman yük vektörlerinin bir araya getirilip toplanması sonucu sisteme ait global rijitlik 
matrisi ve global yük vektörü elde edilmiş olur. $\mathrm{Bu}$ işlemin sonucunda fiziksel problemin davranışını idare eden diferansiyel denklem lineer bir denklem takımına indirgenir (Eşitlik 2).

$$
[\mathrm{K}]\{\mathrm{U}\}=\{\mathrm{F}\}
$$

$\mathrm{Bu}$ eşitlikte yer alan;

$[\mathrm{K}]$ : sistem rijitlik matrisi,

$\{\mathrm{U}\}$ : deplasman vektörü,

$\{\mathrm{F}\}$ : sistem yük vektörüdür.

Şekil 3'te görüldüğü gibi model hareketinin engellendiği doğrultuları ifade eden sınır şartları problem geometrisine uygulanır. $\mathrm{Bu}$ işlem matematiksel olarak, global matris eşitliğinde düğüm noktasının hareketinin engellendiği doğrultulara karşılık gelen satır ve sütunların global matris eşitliklerinden çıkarılması yolu ile yapılmaktadır. Analiz aşamasında ise global matris eşitlikleri çözümlenerek her bir düğüm noktasındaki deplasmanlar elde edilir. Elde edilen düğüm noktası deplasmanları kullanılarak her bir sonlu elemandaki gerilmeler ve birim şekil değiştirmeler hesaplanır. Analizler sonucunda elde edilmiş olan büyük miktardaki veri değerlendirilerek tasarım amaçları için anlaşılır bir kullanıma dönüştürülür [13].
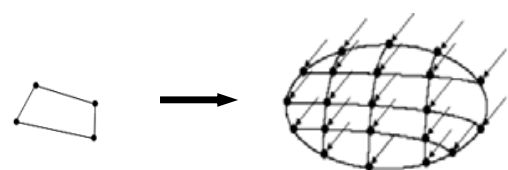

$[\mathrm{k}]_{\mathrm{e}}\{\mathrm{u}\}_{\mathrm{e}}=\{\mathrm{f}\}_{\mathrm{e}}$

$[\mathrm{K}]\{\mathrm{U}\}=\{\mathrm{F}\}$

Eleman eşitliği

Sistem eşitliği

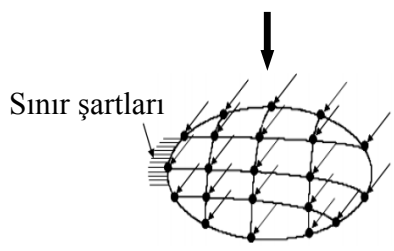

$[\mathrm{K}]\{\mathrm{U}\}=\{\mathrm{F}\}$

Sınır şartlarının uygulanmış hali ile global matris eşitliği

Şekil 3. Global matris eşitliklerinin elde edilmesi
Plaxis 3D, özellikle, temel yapılarının deformasyon analizlerinin gerçekleştirilmesi için geliştirilmiş üç boyutlu bir sonlu eleman programidir. Yapisal elemanlar, yükleme koşulları ve malzeme özellikleri göz önüne alınarak, kum zemin içerisinde yer alan eğik çekme yüküne maruz kazık problemi Plaxis 3D programı kullanılarak modellenmiş ve analiz edilmiştir [14].

\subsubsection{Kum Zemin}

Analizlerde çalışma ortamının geometrik modeli, üç boyutlu ve ele alınan kazık problemine uygun olarak oluşturulmuştur. Geometrik modelin genişliği ve uzunluğu $700 \mathrm{~mm}$, toplam zemin yüksekliği ise $300 \mathrm{~mm}$ 'dir. Zemin modeli olarak Mohr-Coulomb (MC) tercih edilmiştir. Geoteknik mühendisliği problemlerinin analizinde zeminlerin davranışı; az sayıda model parametresine ihtiyaç duyulması, kohezyon ve içsel sürtünme açısı gibi basit fiziksel özellikler kullanılarak göçme kriteri tanımlama olanağının bulunması, geoteknik mühendislerinin gerekli model parametrelerine aşina olmaları ve zemin numuneleri üzerinde gerçekleştirilecek temel zemin mekaniği laboratuvar deneyleriyle bu parametrelerin kolaylıkla elde edilebiliyor olması gibi nedenler ile yaygın olarak Mohr-Coulomb malzeme modeli ile araştırılabilmektedir. Model zemin parametreleri, Brinkgreve ve arkadaşları [15] tarafindan MC zemin modeli için önerilen eşitlikler kullanılarak belirlenmiştir (Eşitlik 3-8).

$$
\begin{array}{ll}
\gamma_{\text {unsat }}=15+4,0 \mathrm{RD} / 100 & {\left[\mathrm{kN} / \mathrm{m}^{3}\right]} \\
\gamma_{\text {sat }}=19+1,6 \mathrm{RD} / 100 & {\left[\mathrm{kN} / \mathrm{m}^{3}\right]} \\
\mathrm{E}_{\text {oed }}=60000 \mathrm{RD} / 100 & {\left[\mathrm{kN} / \mathrm{m}^{2}\right]} \\
\mathrm{E}=[(1+v)(1-2 v) /(1-v)] \mathrm{E}_{\text {oed }} & {\left[\mathrm{kN} / \mathrm{m}^{2}\right]} \\
\phi=28+12,5 \mathrm{RD} / 100 & {\left[{ }^{\circ}\right]} \\
\psi=-2+12,5 \mathrm{RD} / 100 & {\left[{ }^{\circ}\right]}
\end{array}
$$


Kum zemin sıkılığının (RD) \%30 olduğu durumda, eşitlikler kullanılarak hesaplanan MC model parametreleri Çizelge 1'de verilmiştir.

Çizelge 1. Kum zemin için model parametreleri

\begin{tabular}{|l|c|}
\hline & $\begin{array}{c}\text { Kum zemin } \\
(\mathbf{R D}=\% \mathbf{o 3 0})\end{array}$ \\
\hline Malzeme modeli & MC \\
\hline Drenaj tipi & Drenajl 1 \\
\hline$\gamma_{\text {unsat }}\left(\mathrm{N} / \mathrm{mm}^{3}\right)$ & $16,2 \times 10^{-6}$ \\
\hline$\gamma_{\text {sat }}\left(\mathrm{N} / \mathrm{mm}^{3}\right)$ & $19,5 \times 10^{-6}$ \\
\hline $\mathrm{E}_{\text {oed }}{ }^{\text {ref }}\left(\mathrm{N} / \mathrm{mm}^{2}\right)$ & 18 \\
\hline $\mathrm{E}\left(\mathrm{N} / \mathrm{mm}^{2}\right)$ & 15 \\
\hline $\mathrm{c}\left(\mathrm{N} / \mathrm{mm}^{2}\right)$ & 0 \\
\hline$\phi\left(^{\circ}\right)$ & 32 \\
\hline$\psi\left({ }^{\circ}\right)$ & 2 \\
\hline$v$ & 0,25 \\
\hline
\end{tabular}

\subsubsection{Model Kazık}

Analizlerde model kazık, çizgisel eleman (embedded beam) olarak modellenmiştir. Eleman parametreleri olarak çelik malzemenin özellikleri kullanılmış ve girdi parametreleri Çizelge 2'de verilmiştir. Kazık, $\mathrm{D}=25 \mathrm{~mm}$ çapında ve $\mathrm{H}=400 \mathrm{~mm}$ boyunda modellenmiştir.

Çizelge 2. Model kazık için parametreler

\begin{tabular}{|l|l|}
\hline & Değer \\
\hline$\gamma\left(\mathrm{N} / \mathrm{mm}^{3}\right)$ & $77 \times 10^{-6}$ \\
\hline $\mathrm{E}\left(\mathrm{N} / \mathrm{mm}^{2}\right)$ & $2 \times 10^{6}$ \\
\hline
\end{tabular}

\subsubsection{Sonlu Eleman Ağı}

Plaxis 3D'de sonlu elemana ayırma işlemi otomatik olarak gerçekleştirilmekte, ayrıca istenilen bölgelerde ağ sıkılaştırması seçeneği sunulmaktadır. Analizlerde sonlu eleman ağ1 oluşturulurken, sonuçların etkilenmediği en uygun ağ yapısı (mesh) araştırılmıştır. Bu amaçla, farklı mesh durumları göz önüne alınarak bir seri analiz gerçekleştirilmiş ve çekme kapasitesi değerleri karşılaştırılmıştır. Kazık gömülme oranının $\mathrm{L} / \mathrm{D}=8$, zemin sıkılığının $R D=\% 30$ ve yük açısının $\alpha=0^{\circ}$ olduğu durumda analizler gerçekleştirilmiştir. Analizlerde; mevcut çok kaba (very coarse), kaba (coarse), orta (medium), ince (fine) ve çok ince (very fine) mesh seçenekleri kullanılmıştır. Analizlerden elde edilen sonuçlar toplu olarak Çizelge 3'te verilmiştir. Şekil 4'te farklı mesh durumları için çekme kapasitesi-deplasman eğrileri, Şekil 5'te ise çekme kapasitesi-eleman sayısı ilişkisi görülmektedir.

Çizelge 3'te ve Şekil 4, 5 ve 6'da çekme kapasitesinin ăg sıkılığından etkilendiği görülmektedir. Çok kaba mesh kullanılması durumunda çekme kapasitesi değeri, çok ince mesh kullanılması durumuna göre yaklaşık 3 kat daha fazla çıkmıştır. Mesh analizlerinden, mesh etkisinin ince ve çok ince mesh durumlarında oldukça azaldığ1 görülmüş ve analizlerde çözüm süresi de dikkate alınarak sonlu eleman ağı ince (fine) mesh seçeneğiyle oluşturulmuştur. Ayrıca analizler sonucunda elde edilen deplasman dağılımları, düşey çekme yüküne maruz tekil bir kazığın göçme mekanizmasını başarılı bir şekilde yansıtmıştır (Şekil 6). Şekil 7'de problem modeli ve sonlu eleman ağı görülmektedir.

Çizelge 3. Farklı ağ sıkılıkları (mesh) için analiz sonuçları

\begin{tabular}{|l|c|c|c|c|c|}
\hline \multirow{2}{*}{} & \multicolumn{5}{|c|}{ Sonlu eleman ağının sıkılı̆̆ } \\
\cline { 2 - 6 } & Çok kaba & Kaba & Orta & İnce & Çok ince \\
\hline Eleman sayısı & 1085 & 2628 & 11825 & 37370 & 106342 \\
\hline Düğüm sayısı & 1886 & 4249 & 17503 & 53251 & 148571 \\
\hline Eleman boyutu (mm) & 110,90 & 83,18 & 55,45 & 38,82 & 27,73 \\
\hline Çekme kapasitesi (N) & 134,34 & 83,85 & 62,74 & 44,02 & 43,51 \\
\hline
\end{tabular}




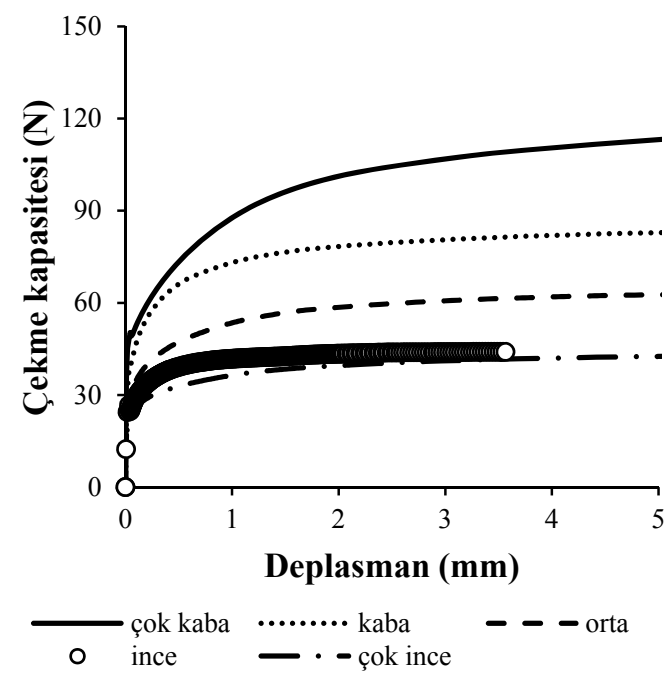

Şekil 4. Sonlu eleman sıkılığının çekme kapasitesideplasman ilişkisine etkisi

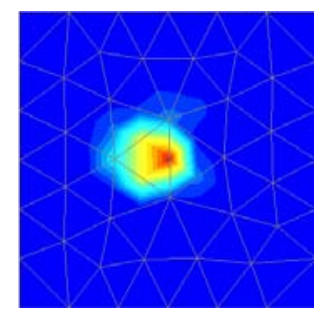

(a) çok kaba

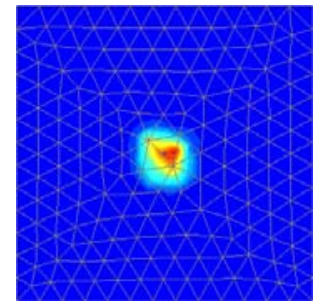

(c) orta

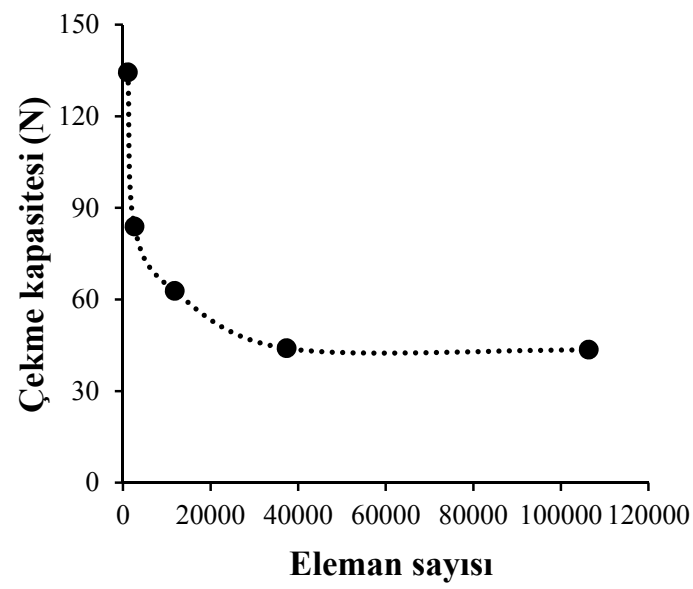

çok kaba-1085 ince- 37370 orta-11825 çok ince-106342

Şekil 5. Çekme kapasitesi-eleman sayısı ilişkisi
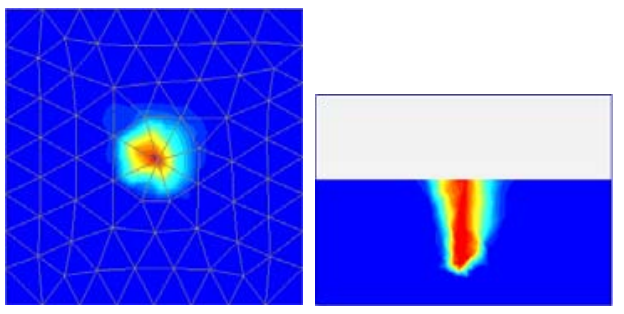

(b) kaba
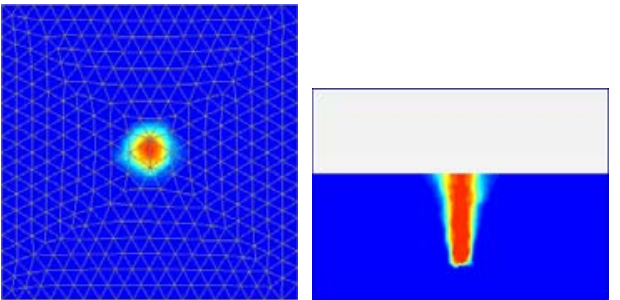

(d) ince
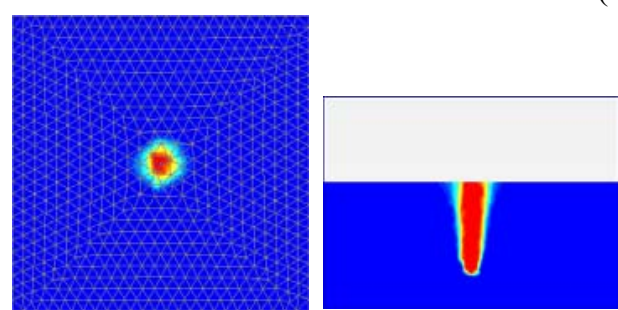

(e) çok ince

Şekil 6. Sonlu eleman sıkılığının deplasman dağılımına etkisi 


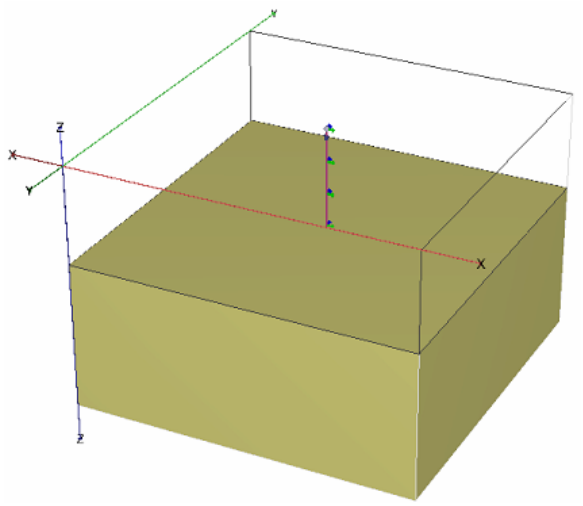

(a) problem modeli

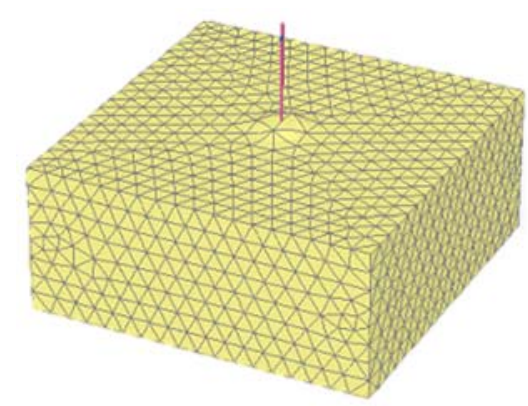

(b) sonlu eleman ağ

Şekil 7. Üç boyutlu sayısal model

\subsection{Teorik Yöntem}

Broms [16] yatay açıyla çekilmiş düşey bir kazı̆ğın çekme kapasitesini aşağıdaki eşitliği kullanarak hesaplamıştır.

$\mathrm{P}_{\mathrm{L}}=0,5 \gamma^{\prime} \mathrm{DL}^{2} \mathrm{~K}_{\mathrm{p}}$

Bu eşitlikte yer alan;

$\mathrm{P}_{\mathrm{L}}$ : Düşey kazı̆̆ın yatay kapasitesi,

$\gamma^{\prime}:$ Zeminin birim hacim ağırlığı,

D : Kazık çapı,

L : Kazık boyu,

$\mathrm{K}_{\mathrm{p}}$ : Pasif toprak basincı katsayısı

Eğik çekme yüküne maruz kazık probleminde kazık kapasitesi, hem yatay hem de düşey kapasitenin bir fonksiyonudur [17]. Düşey eksen doğrultusunda uygulanan yük, çekme kapasitesi doğuracak ve meydana gelen göçme çekmeden kaynaklı olacaktır. Ancak uygulanan yük düşey eksenden saparsa yani yükün eğimi artarsa, yatay yönde bir kapasite oluşacak ve bu durum yatay yönde de göçme meydana gelmesine sebep olacaktır. Bu sebeple eğik yükleme problemlerinde her iki göçme durumu da dikkate alınmalıdır. Kazığın çekme ve yatay kapasitesitelerinin birbirinden bağımsız olduğu varsayımına göre, her iki kapasiteden kazı̆̆ın toplam kapasitesine geçiş mümkün olabilmektedir [3].

$\mathrm{Bu}$ çalışmada, yatay yüke $\left(\alpha=90^{\circ}\right)$ maruz tekil kazık kapasitesinin hesabı için Broms [16] tarafından önerilen eşitlik kullanılarak sayısal analizin doğrulanması amaçlanmıştır. Sonrasında yapılan parametrik çalışmada, kazık kapasitesinin yük açısından ne şekilde etkilendiği incelenmiştir. Analizler sonucunda elde edilen kazık kapasitesinden düşey ve yatay doğrultudaki kazık kapasitelerine geçiş yapılmıştır.

\subsection{Problemin Tanıtımı}

Problemde araştırılan parametre Şekil 8'de gösterilmiştir. Çalışma boyunca; tek bir gömülme oranına sahip $(\mathrm{L} / \mathrm{D}=8)$ tekil kazıkta, yükün düşey eksenle yaptığı açının $(\alpha)$ kazık kapasitesine etkisi incelenmiştir.

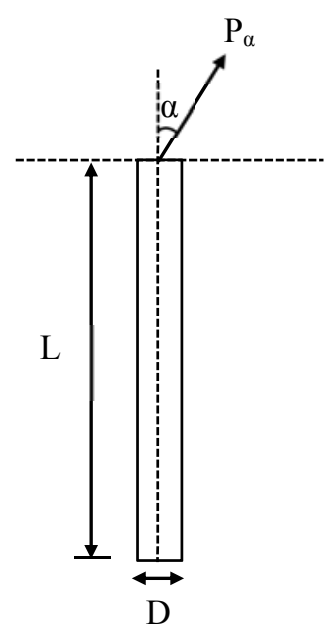

Şekil 8. Problemin gösterimi 


\section{BULGULAR VE TARTIŞMA}

Sayısal modelleme yapılan bu çalışmada, yükün düşey eksenle yaptığı açının $(\alpha)$ kazık kapasitesine etkisi araştırılmıştır. $90^{\circ}$ çekme açısına sahip kazıkta yapılan sayısal analizden elde edilen sonuç, Broms [16] tarafindan önerilen eşitlikle karşılaştırılmış ve sayısal analizin kazık kapasitesini tahminindeki başarısı araştırılmıştır. Sonuçlar; kazık kapasitesi-deplasman, kazık kapasitesi- $\alpha$, zemin yüzeyinde ve kazık boyunca meydana gelen deplasman dağılımlarını içeren şekiller ile sunulmuştur. Analizler sonucunda elde edilen kazık kapasitesi değerleri, belirgin bir göçme yükünün olmaması nedeniyle, kazık çapının \%10’u kadar oturmaya karşılık gelen yük değerleri olarak alınmıştır.

Sayısal analiz ve Broms [16] tarafından önerilen eşitlik kullanılarak elde edilen kazık kapasitesi sonuçları Çizelge 4'te sunulmuştur.

Çizelge 4. Sayısal analizin doğrulanması

\begin{tabular}{|l|c|}
\hline & Kazık kapasitesi (N) \\
\hline Sayısal analiz & 25,94 \\
\hline Broms [16] & 26,36 \\
\hline
\end{tabular}

Her iki yöntemle elde edilen sonuçların oldukça uyumlu olduğu görülmüştür. Aradaki yaklaşık \%1,5'lik farkın makul olduğu kabul edilmiştir. Sonrasında yapılan parametrik çalışmada, uygulanan yükün düşey eksenle yaptığı açının artmasıyla kazık kapasitesinin azaldığı belirlenmiştir. Kazık kapasitesini oluşturan düşey ve yatay bileşenlerin değişimi Çizelge 5'te verilmiştir.

Çizelge 5. Sayısal analizler sonucunda elde edilen kazık kapasiteleri

\begin{tabular}{|c|c|c|c|}
\hline $\begin{array}{c}\text { Yük } \\
\text { açısı } \\
(\boldsymbol{\alpha})\end{array}$ & $\begin{array}{c}\text { Düşey } \\
\text { kapasite } \\
(\mathbf{N})\end{array}$ & $\begin{array}{c}\text { Yatay } \\
\text { kapasite } \\
(\mathbf{N})\end{array}$ & $\begin{array}{c}\text { Kazık } \\
\text { kapasitesi } \\
(\mathbf{N})\end{array}$ \\
\hline $0^{\circ}$ & 43,75 & - & 43,75 \\
\hline $15^{\circ}$ & 39,81 & 10,67 & 41,21 \\
\hline $30^{\circ}$ & 31,72 & 18,32 & 36,63 \\
\hline $60^{\circ}$ & 13,67 & 23,68 & 27,34 \\
\hline $90^{\circ}$ & - & 25,94 & 25,94 \\
\hline
\end{tabular}

Yükün düşey eksenle yaptığı açının ( $\alpha$ ) artmasıyla, kazıkta meydana gelen düşey kapasite azalmışken yatay kapasite artmıştır. Şekil 9 ve 10'da, sırasıyla, sayısal analizlerden elde edilen kapasite-deplasman ve kapasite-yük açısı ilişkileri verilmiştir. Analiz sonuçlarından, kazık kapasitesinin eğik yükleme durumundan olumsuz etkilendiği görülmüştür. Düşey çekme açısındaki $\left(\alpha=0^{\circ}\right)$ kazık kapasitesi, $60^{\circ}$ çekme açısına maruz kazık kapasitesinden yaklaşık \%60 daha fazla çıkmıştır.

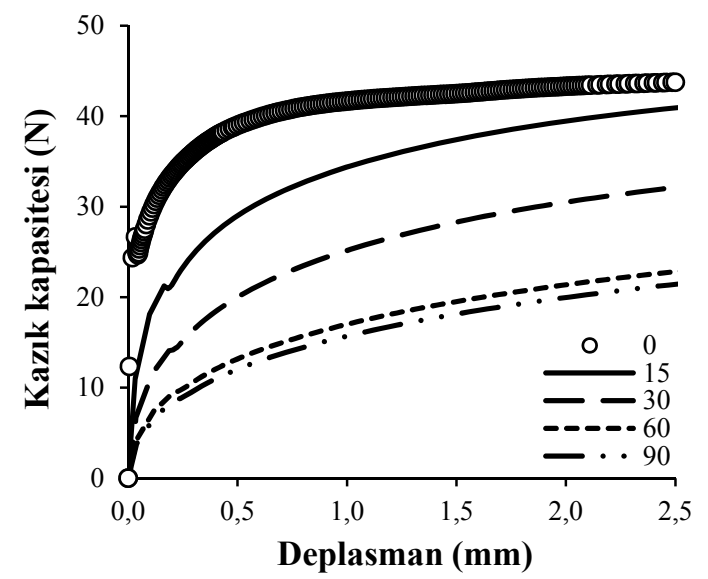

Şekil 9. Yük açısı $(\alpha)$ 'nın kazık kapasitesideplasman ilişkisine etkisi

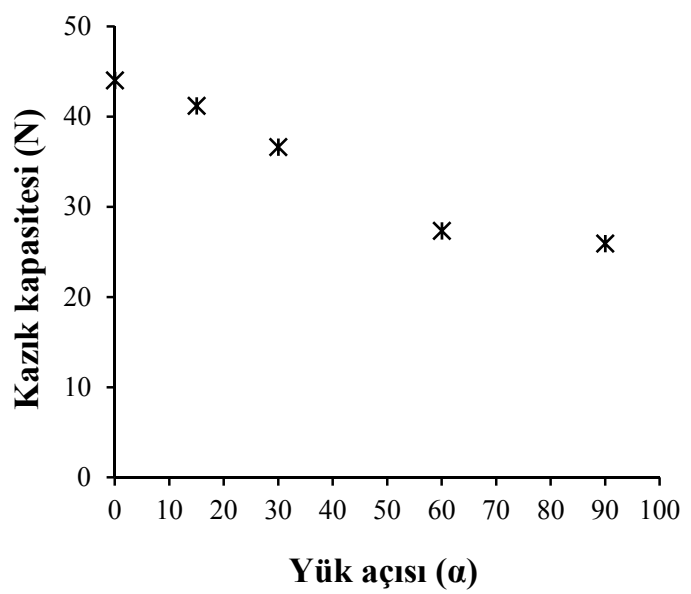

Şekil 10. Yük açısı ( $\alpha$ )'nın kazık kapasitesine etkisi

Şekil 11 ve 12 'de yük açısının zemin yüzeyinde ve kazık boyunca meydana getirdiği yatay daplasman dağılımları verilmiştir. 
Yük açısının artmasıyla zemin yüzeyinde meydana gelen deplasman yoğunluğu yük açısının verildiği doğrultudaki zemin bölgesini etkilemiş ve deplasmanların daha geniş bir alana yayılması söz konusu olmuştur. Yük açısının $0^{\circ}$ olduğu durumda, zemin yüzeyinde meydana gelen yatay deplasmanlar çok azken, yük açısının artmasıyla birlikte zemin yüzeyinde meydana gelen yatay deplasmanların büyüklüğü ve yayıldığı alan artmıştır (Şekil 11).

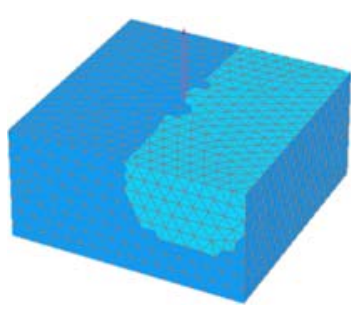

(a) $\alpha=0^{\circ}$

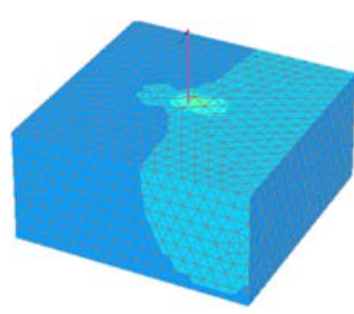

(c) $\alpha=30^{\circ}$

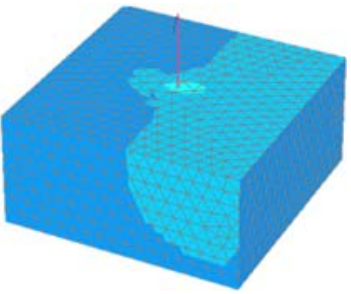

(b) $\alpha=15^{\circ}$

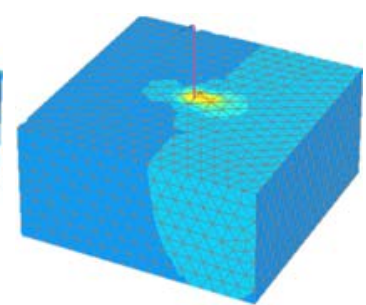

(d) $\alpha=60^{\circ}$

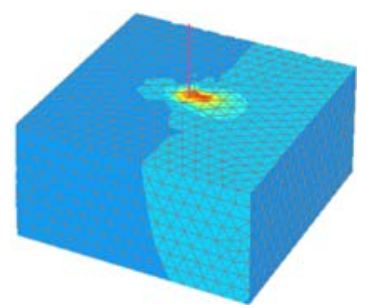

(e) $\alpha=90^{\circ}$

Şekil 11. Yük açısı $(\alpha)$ 'nın zemin yüzeyindeki yatay deplasman dağılımına etkisi

Şekil 12'de ise yük açısının artmasıyla kazık boyunca meydana gelen yatay deplasman yoğunluğu, yük açısının verildiği doğrultudaki zemin bölgesini etkilemiş ve o bölgedeki deplasman yoğunluğu artmıştır.

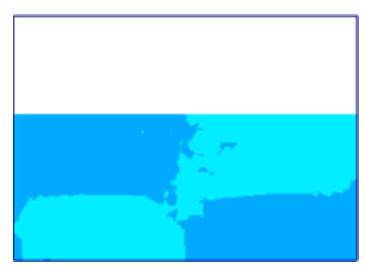

(a) $\alpha=0^{\circ}$

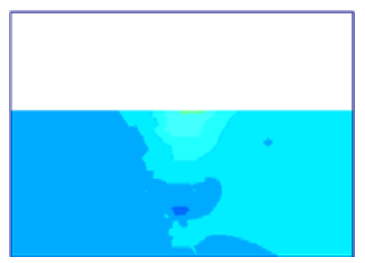

(c) $\alpha=30^{\circ}$

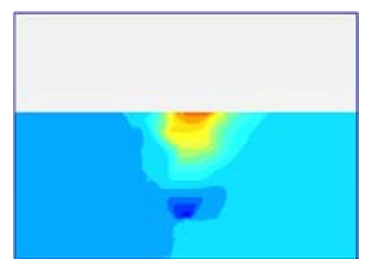

(e) $\alpha=90^{\circ}$

Şekil 12. Yük açısı ( $\alpha$ )'nın kazık boyuncaki yatay deplasman dağılımına etkisi

\section{SONUÇLAR}

Bu çalışmada, eğik çekme yüküne maruz kazık davranışı sayısal olarak incelenmiş ve elde edilen sonuçlar aşağıda sunulmuştur.

- Çekme kapasitesinin ağ sıkılığından etkilendiği görülmüştür. Çok kaba mesh kullanılması durumunda çekme kapasitesi değeri, çok ince mesh kullanılması durumuna göre yaklaşık 3 kat daha fazla çıkmıştır. Ayrıca analizler sonucunda elde edilen deplasman dağılımları, düşey çekme yüküne maruz tekil bir kazığın göçme mekanizmasını başarılı bir şekilde yansıtmıştır.

- $90^{\circ}$ çekme açısına sahip kazıkta yapılan sayısal analizden elde edilen sonuç, Broms [16] tarafından önerilen eşitlik ile karşılaştırılmış ve sonuçlar uyumlu çıkmıştır.

- Yükün düşey eksenle yaptığı açının artmasıyla kazık kapasitesi azalmıştır.

- Yük açısının artmasıyla zemin yüzeyinde ve kazık boyunca meydana gelen deplasmanlar, yük 
bileşeninin arttığ 1 doğrultudaki zemin bölgesini etkilemiştir. Açının artmasıyla, yatay doğrultuda meydana gelen deplasman yoğunluğu daha fazla olmuştur.

\section{TEŞEKKÜR}

Bu çalışmanın birinci yazarı TÜBİTAK tarafından yurt içi doktora bursu ile desteklenmektedir. Birinci yazar, bu destek için TÜBITTAK'a teşekkürlerini sunmaktadır. Bu çalışma Çukurova Üniversitesi Bilimsel Araştırma Projeleri Koordinasyon Birimi tarafindan desteklenmiştir (Proje No: FBA-20178775).

\section{KAYNAKLAR}

1. Maviş, S., 2013. Düşey ve Eğik Kazıklı İskele Yapılarında Zemin-Kazık Etkileşiminin Detaylı ve Basitleştirilmiş Modeller ile İrdelenmesi. Yıldız Teknik Üniversitesi, Yüksek Lisans Tezi, 90, İstanbul.

2. Chattopadhyay, B.C., Pise, P.J., 1986. Uplift Capacity of Piles in Sand. Journal of Geotechnical Engineering, 112(9), 888-904.

3. Ismael, N.F., 1989. Field Tests on Bored Piles Subject to Axial and Oblique Pull. Journal of Geotechnical Engineering, 115(11), 1588-1598.

4. Veeresh, C., Narasimha Rao, S., 1996. Vertical Pullout Capacity of Model Batter Anchor Piles in Marine Clays. Marine Georesources \& Geotechnology, 14(3), 205-215.

5. Al-Shakarchi, Y.J., Fattah, M.Y., Kashat, I.K., 2004. The Behaviour of Batter Piles under Uplift Loads. International Conference on Geotechnical Engineering, 105-114.

6. Mroueh, H., Shahrour, I., 2007. Response of Piles to Inclined Uplift Loads Influence of the Soil-Pile Interface. European Journal of Computational Mechanics, 16(3-4), 419-435.

7. Mroueh, H., Shahrour, I., 2009. Numerical Analysis of the Response of Battered Piles to Inclined Pullout Loads. International Journal for Numerical and Analytical Methods in Geomechanics, 33(10), 1277-1288.

8. Korkmaz, Ş., 2012. Düşey ve/veya Eğik Kazıklı İskele Yapılarında Zemin-Yapı Etkileşimi.
Yıldız Teknik Üniversitesi, Yüksek Lisans Tezi, 112, İstanbul.

9. Nazir, A., Nasr, A., 2013. Pullout Capacity of Batter Pile in Sand. Journal of Advanced Research, 4(2), 147-154.

10. Li, Z., Kotronis, P., Escoffier, S., 2014. Numerical Study of the 3D Failure Envelope of a Single Pile in Sand. Computers and Geotechnics, 62, 11-26.

11. Reddy, K.M., Ayothiraman, R., 2015. Experimental Studies on Behavior of Single Pile under Combined Uplift and Lateral Loading. Journal of Geotechnical and Geoenvironmental Engineering, 141(7), 04015030.

12. Jiang, X., Li, K., 2016. Research on Pull-out Mechanical Characteristics of Pile Foundation in Submerged Floating Tunnel. Procedia Engineering, 166, 389-396.

13. Uncuoğlu, E., $2009 . \quad$ Kohezyonsuz Zeminlerdeki Kazıkların Yatay Yük ve Moment Etkisi Altındaki Davranışlarının Analizi. Çukurova Üniversitesi, Doktora Tezi, 277, Adana.

14. Plaxis 3D.AE.02, 2016. Plaxis bv, Delft, The Netherlands.

15. Brinkgreve, R.B.J., Engin, E., Engin, H.K., 2010. Validation of Empirical Formulas to Derive Model Parameters for Sands. Numerical Methods in Geotechnical Engineering, 137-142.

16. Broms, B.B., 1965. Discussion on, Piles in Cohesionless Soil Subject to Oblique Pull. Journal of Soil Mechanics and Foundations, 91(4), 199-205.

17. Poulos, H.G., Davis, E.H., 1980. Pile Foundation Analysis and Design. John Wiley and Sons, NY. 
